\title{
The Application of Marine Sciences in THE COMING DECADES
}

\author{
By Melbourne Briscoe and David Evans
}

The best argument

for sustained and

improved basic

research funding in

academia and in the

federal agencies is

an improved transfer

of basic research

results into

applications; . . .
C portant editorial in Science (15 Jan 93, 296-297), "Marine Sciences in the Coming Decades," which is based on a 1992 study by the Ocean Studies Board of the National Research Council, called "Oceanography in the Next Decade: Building New Partnerships." He points out that today's societal applications of oceanography are built on yesterday's basic. curiosity-driven research; further, he suggests that tomorrow's support of such basic oceanographic research is endangered by shifts in national priorities and by a general tendency toward short-term benefits rather than a longer view. He argues that "the best oceanographic knowledge has not often been used [in policy decisions]." Finally, he suggests that the mission-oriented federal agencies (for example, NOAA, DOE, and EPA) should, "sustain the funding for basic scientists in these [mission] organizations, although the payback is possibly many years in the future." He closes with the call for a mechanism that will permit "rational discussion and allocation of resources across the multitude of agencies involved." There is an implication in his editorial that the mission agencies should provide a fraction of their funds to support basic research in academia, for it is upon this research base that the agencies' programs depend.

Wunsch's arguments and suggestions are close to the mark, but they leave out a critical part of the overall picture: in addition to the strong basic research community - found in many parts of academia and some parts of the federal agenciesthe nation needs a much improved mechanism to ensure that societal benefits are in fact obtained from the results of the curiosity-driven research. The case is persuasive that societal applications are not generally limited by lack of good basic research, but rather by the inability of the mission agencies and the other users of oceanography to

M. Briscoe, and D. Evans, Ocean and Earth Sciences, NOAA. National Ocean Service, Silver Spring, Maryland 20910, USA. get access to, to understand, to reshape, and to exploit the extant results of the research community. Given this reality, from which one could conclude that more than enough basic research might already be going on, how does one extend Wunsch's arguments for a new academic-federal partnership and for new mechanisms to ensure a strong basic research effort in the future?

Further, in addition to this problem of what the Navy calls "transition," i.e., the movement of research results into applications, there is the less defined but also important problem of whether the topics and kind of basic research going on are such as to engender useful applications. Two examples are the quest for another decimal place in the value of some number (much hated by funding agencies), or finding an alternate way to prove some idea that has already been proven (also of low priority for funding agencies). This essay will concentrate on the problem of transition.

The thesis presented here is as follows:

The best argument for sustained and improved basic research funding in academia and in the federal agencies is an improved transfer of basic research results into applications; if the government and the public see the benefits arising from research expenditures, then they will be more willing to see those research expenditures be maintained and even increased, even in today's economic climate. Demonstrating the value of the current level of research is required before making a case for more research. An effective means of demonstrating the value might be a credible documentation of how past results have been incorporated into current products, developments, or policies.

The application of research is not generally limited by the amount of research being done: that is, more good research is not likely to change significantly the amount that is being applied. [In gas dynamics we call this choked flow: the flow rate is dependent on downstream conditions and not on pressure on the nozzle.] Rather, the application of research is limited by the capability of the mission agencies and other application sites to 
understand the research results and to be able to modify the results into the forms that actually solve some applied problems. This understanding and modifying typically requires applications people who have quality and training similar to those who produced the research results, but who have a different motivation in their careers: they prefer to be exploiters and extenders rather than producers of new knowledge, for they prefer to see their work be applied directly to some societal problem of substance. However, this understanding also requires a community of researchers who are able and willing to communicate their results to others in terms that may be less than scientific, or even less than accurate. Most researchers abhor describing their work in lay terms and without endless caveats; most decision makers and policy people abhor endless waffling and details of equations or instruments. How many times have you been asked, "So What?" about your research. How many times have you been able to provide an answer satisfactory to the questioner? There is some shared blame here: the researchers need to explain things better and more often and in less ambiguous terms; the applications community has to learn to be a better translator and to make better use of opportunities; and the policy and decision makers have to learn to accept a degree of fuzziness in what they are told. Most societally relevant problems do not admit black and white solutions.

The time-scale of application of academic research is long, typically a generation. There are counter-examples of faster movement of research into application, but in general the pace is dependent on students graduating and moving into the work force in the mission agencies and oceanographic industries. The students bring with them the new knowledge and approaches developed by their professors. However, if the loop becomes closed and professors graduate only students who become professors, where is the benefit to the nation? The thesis here is the more students who move into industry and government, the more likely the knowledge they learned will become part of applications, and the faster it will happen. Suggestion: for the health of the research community and for the benefit of the nation, our educational system should cease treating an academic research career as the only successful thing a graduate can do. Rather, graduates moving into industries and government should be viewed as an essential, important part of the system, not as losers in the quest for a "real" job.

The examples of rapid transition of research to application all depend upon critical people in the mission agency or industry who have access to the emerging research results indirectly through journal articles or contact with the researchers, or directly through participation in the research process itself, and who are able to understand and appreci- ate the emerging result in the context of required or potential applications. This is often given as a reason that the mission agencies and industries should have research divisions, but if the research division is isolated from the applications part of the organization, then the same problems occur as with research in the universities without the relief valve of students who someday become part of the applications groups. Indeed, the isolation is as often cultural and social as it is physical.

Wunsch's point is that today's societal applications of oceanography are built on yesterday's basic, curiosity driven research; we agree, but argue that it takes a generation for this to happen unless an all-too-rare set of circumstances exist involving critical people in the application organizations.

Wunsch observes that the best oceanographic knowledge has not often been used in policy decisions; we agree, but argue that the onus is equally on the researchers to communicate-or at least to participate in the communication of - the research results to the policy makers in a form they can understand and use. All too often, the researcher says, "that's not my job," and consequently the job does not get done. It may be true that a piece of research is not finished until it is published in a peer-reviewed journal, but it is also true that the research is of little value to society until it - or a derivative of it-is turned into an application. If the product of research is only journal publications, research has the danger of being an inbred. circular activity. [Research at universities is usually justified in terms of its educational benefits to students through the professional advancement of the faculty. Arguably, that educational responsibility should extend to the users of the research results rather than being viewed as a burdensome addition to their plate.]

Wunsch concludes that the looming problem is that the federal agencies do not coordinate their efforts in such a way as to ensure a strong research effort in the future, upon which they can build. We agree, but argue that without an equally strong effort to move the research results into applications, the coordination will be for naught. We note, however, that progress in agency coordination has been significant in recent years, especially in oceanography. For example. the Tropical Ocean Global Atmosphere (TOGA) program has been a nearly seamless coordination between the Nation Science Foundation (NSF) and National Oceanic and Atmospheric Administration (NOAA), and the Joint Global Oceans Flux Studies (JGOFS) Indian Ocean program has involved NSF and the Office of Naval Research (ONR) joint management. planning and funding. Similar coordination at the applications end has not been as successful.

Wunsch argues for basic research support from the mission agencies since their future depends

\section{... research is}

of little value to

society until it . . . is

turned into an

application . . . 


\section{The decades}

following World War II

were the glory years

for oceanography,

during which time the

field was protected

and nurtured in an

unrealistic funding

environment. upon the basic research. This misses the point that there is considerable basic research that already goes on without the support of the mission agencies and that this research has little impact on the agencies, by Wunsch's own admission. Why is more research needed, that will have little impact on the agencies? The problem is not insufficient research, it is insufficient application of the research that is already going on. It may also be that the research that is already going on is not relevant to the mission agencies: to the extent this is true, how does more of it help?

The decades following World War II were the glory years for oceanography, during which time the field was protected and nurtured in an unrealistic funding environment. The next decades must see the evolution to a mature oceanographic field that treats research and applications as equally worthy endeavors and that trains its best students to be involved in both.

Wunsch expresses great nostalgia for the past and its days of funding and flexibility; but nostalgia is not what it used to be and neither is oceanography and its funding environment in the future. Oceanography has matured and has produced some remarkable advances and an impressive breadth and depth of knowledge: the future will be constructed by using those advances and that knowledge, as well as developing new knowledge for the future beyond.

Here are some suggestions for how to improve the application of research results, which we submit is the fundamental problem.

1. Encourage the academic researchers to spend some time working with the applications community, including policy makers. No one is better prepared to communicate and interpret research results than the researchers themselves, but the most effective forms of that communication need to be learned as surely as does the traditional "journal" style of writing. Rather than being viewed as being detrimental to a researcher's career to spend time this way, it should be viewed as an asset to a researcher's career to be capable of going beyond just publishing in journals. Even if all researchers may not wish to spend time this way, those who do should not be denigrated by those who don't. Some view publishing as the pinnacle of a career; we submit it is just a rock at the bottom of a very steep mountain.

2. Encourage the applications community to spend some effort helping the academic researchers go beyond the journal-publication stage and to spend some time helping the researchers understand what the application areas are. There is little value in a mission agency telling a basic researcher what to work on; there is great merit in the agency telling the basic researcher what its problems are, so that whatever captures the researcher's fancy will have a better chance of actually being applied to the agency's problems. The point is not to require the basic researcher to do applied research, but rather to help the basic researcher do applicable research. The existence and nature of the applied problems can help to stimulate the researcher's curiosity.

3. Reconsider the concept of research divisions in the mission agencies. The more separation there is organizationally, physically, intellectually, and culturally between an agency's researchers and its applications people, the less chance the research will be applicable to the agency's problems. The integration of research and applications in an agency does have the danger of the pervasive influence of the many problems that need immediate attention; this could draw the researchers away from their main task. But consider the alternative: researchers who are not cognizant of the problems of the agency, and so follow their curiosity but miss the targets, or at least only hit them by accident. This is, by and large, our current system, and it is not good enough. We need more integration of the people who do research with those who hope to use it. The integration should be organizational, social, and personal. The artificial separation of basic research from applications, while justifiable in academe, is clearly inappropriate for the mission agencies.

"I shot an arrow into the air; and where it landed, I painted a target." This is curiosity driven research when there is no knowledge of where the targets are. The goal of the mission agencies and industries should be to help the researchers know where the targets are: curiosity is not diminished. it is just directed.

\section{Epilogue}

Wunsch's editorial is clearly not focussed on the applications of research; his focus is the intrinsic value of curiosity driven research and the danger that it might go away in time. Our purpose here is to suggest that this focus misses an essential point: the products of the research need to bear fruit. Without this parallel concern, the research is to no end other than the pursuit of intellectual challenges. Although this is a vital part of society and a satisfying career, it is hardly a compelling argument for continued or increased funding. 